\title{
The role of progesterone in endometrial angiogenesis in pregnant and ovariectomised mice
}

\author{
Lisa M Walter, Peter A W Rogers and Jane E Girling \\ Centre for Women's Health Research, Monash University Department of Obstetrics and Gynaecology, \\ Monash Medical Centre, 246 Clayton Rd, Clayton, Victoria, Australia 3168
}

Correspondence should be addressed to J Girling; Email: jane.girling@med.monash.edu.au

\begin{abstract}
The role of progesterone (and oestrogen) in endometrial angiogenesis remains controversial. The aims of this study were to quantify endometrial angiogenesis in pregnant mice and to investigate the role of progesterone in promoting endothelial cell proliferation in ovariectomized mice. Uteri were collected on days 1 to 4 of pregnancy when circulating progesterone concentrations were increasing, prior to implantation. Before dissection, mice were injected with bromodeoxyuridine (BrdU) enabling proliferating endothelial cells to be quantified with CD31/BrdU double-immunohistochemistry. There was a significant increase in proliferating endothelial cells on day 3 of pregnancy when plasma progesterone also increased. To determine if this endothelial cell proliferation was due to progesterone, an experiment was performed on ovariectomised mice. One group was treated with a single oestradiol injection on day 8 after ovariectomy, followed by a no-treatment day and three consecutive daily injections of progesterone. Other groups were treated with either the vehicle, oestradiol or progesterone injections only; all were dissected on day 13 following ovariectomy. Unexpectedly, mice treated with progesterone-only had the highest amount of endothelial cell proliferation and oestrogen priming was found to significantly reduce this progesterone-induced endothelial cell proliferation. To determine if this proliferation is mediated by vascular endothelial growth factor (VEGF), a further experiment in which VEGF anti-serum was administered concurrently with the progesterone injections was performed. Endothelial cell proliferation was reduced but not abolished suggesting progesterone-induced endometrial angiogenesis is only partly mediated by VEGF. Results indicate that oestrogen priming is not required for progesterone to stimulate endometrial endothelial cell proliferation and that oestrogen inhibits progesterone-induced angiogenesis in ovariectomised mice.

Reproduction (2005) 129 765-777
\end{abstract}

\section{Introduction}

Angiogenesis (the growth of new blood vessels from preexisting vasculature) occurs concomitant with the growth and regression of the human endometrium to provide an uninterrupted blood supply to this rapidly changing tissue (Smith 1998). Endometrial angiogenesis is under the overall control of the ovarian steroids oestrogen and progesterone, via their receptors, which function as hormoneactivated transcription factors and modulators of gene expression in target cells (Barkhem et al. 1998, Hewitt \& Korach 2000). The downstream pathways by which oestrogen and progesterone regulate endometrial angiogenesis still remain unclear.

To date, most research has focussed on the effects of oestrogen on endometrial angiogenesis and in general oestrogen is thought to stimulate new vessel growth. In humans, elongative angiogenesis has been demonstrated in the endometrium during the proliferative phase of the menstrual cycle (Gambino et al. 2002). However, although oestrogen is known to stimulate epithelial (glandular and luminal) and stromal cell proliferation in the mouse (Martin \& Finn 1968), there have been conflicting results concerning endometrial angiogenesis. Ma et al. (2001) hypothesized that oestrogen is anti-angiogenic in the mouse uterus. They found that oestrogen stimulated an initial rapid, transient induction of vascular endothelial growth factor (VEGF) and receptors VEGFR2 (FIk1) in the stromal bed. As there was increased vascular permeability in the uterus, but reduced uterine vascular density and decreased stromal endothelial Flk1 expression during the late oestrogenic response, these results suggested an inhibitory role for oestrogen. Hastings et al. (2003) reported that while oestrogen increased vascular permeability, cellular mitosis, and DNA and RNA synthesis, it did not stimulate an increase in endothelial cell proliferation. In contrast to Hastings, Heryanto \& Rogers (2002) 
observed a rapid induction of endometrial endothelial cell proliferation within $24 \mathrm{~h}$ of oestrogen treatment in ovariectomised mice, suggesting a rapid angiogenic response. This rapid proliferative response of endometrial endothelial cells to oestrogen is mediated by VEGF, a potent endothelial cell mitogen (Albrecht et al. 2003 b, Heryanto et al. 2003). The administration of either an anti-VEGF antibody or VEGF receptor inhibitor significantly inhibited the oestrogen-mediated endometrial endothelial cell proliferation in ovariectomised mice (Heryanto et al. 2003b).

In contrast to oestrogen, only a few studies have been performed considering the role of progesterone in endometrial angiogenesis. Gambino et al. (2002) have shown that a form of branching angiogenesis (such as intussusception or sprouting) occurs in the human endometrium during the secretory phase of the menstrual cycle. In rats, endometrial endothelial cell proliferation increased significantly during early pregnancy when plasma progesterone concentrations are increasing prior to implantation (Goodger \& Rogers 1993). It was also found that progesterone increased vascular density in ovariectomised mice while having little effect on vascular permeability (Ma et al. 2001). While most of the in vivo research into progesterone supports a role for this steroid in endometrial angiogenesis, there are conflicting results from in vitro studies, either supporting a pro-angiogenic role for progesterone (Kayisli et al. 2004) or suggesting an anti-angiogenic role for progesterone (Vazquez et al. 1999). Therefore, there is a need for further research to elucidate the role of progesterone in this process.

The aim of this research was to investigate the role of progesterone in endometrial angiogenesis. Initially, endometrial endothelial cell proliferation was quantified during early pregnancy in the mouse (prior to implantation). Proliferation of stromal and luminal epithelial cells was also quantified to investigate the differential effects of progesterone in the other endometrial compartments. We hypothesised that endometrial endothelial cell proliferation would increase in concert with increasing plasma progesterone concentrations. A hormone regime was then developed that would stimulate endometrial endothelial cell proliferation in ovariectomised mice. We hypothesised that progesterone would stimulate endometrial endothelial cell proliferation in ovariectomised mice, but that pre-treatment of the endometrium with oestrogen would be required. We also hypothesised that progesterone-induced endometrial endothelial cell proliferation would be mediated by VEGF.

\section{Materials and Methods}

\section{Animals}

Adult female mice (7-13 weeks, $18-28 \mathrm{~g}, \mathrm{C} 57 \mathrm{BL} / 6 \mathrm{~J} \times$ CBA; Monash Animal Services, Monash University, Victoria, Australia) were housed under controlled environmental conditions $\left(20^{\circ} \mathrm{C}, 12 \mathrm{~h}\right.$ light per day) and provided with food and water ad libitum. This study was approved by the Monash Medical Centre Animal Ethics Committee A.

\section{Study one}

Female mice were housed overnight with stud males, and the presence of a vaginal plug the following morning indicated successful mating. The day of a successful mating was considered day 1 of pregnancy. To ensure that the steroidal conditions of the endometrium at the time of the study were under maternal rather than fetal control, pregnant mice were dissected on days 1 to 4 of pregnancy $(n=4-5)$ when circulating progesterone concentrations were increasing, but prior to implantation on day 5 (Finn \& Martin 1969).

Four hours prior to dissection, mice received an i.p. injection of bromodeoxyuridane (BrdU; $40 \mathrm{mg} / \mathrm{kg}$ body weight, $500 \mu \mathrm{l}$, Sigma-Aldrich Co., St Louis, MO, USA), enabling visualisation of proliferating cells by immunohistochemistry. The mice were anaesthetized with an i.p. injection of Avertin (25 mg/100 g body weight, 2,2,2-tribromoethanol (Aldrich Chemical Company, Milwaukee, USA) in butan-2-ol (BDH Laboratory Supplies, Poole, England)). Blood was collected by cardiac puncture and the plasma stored at $-80^{\circ} \mathrm{C}$. Plasma progesterone concentrations were later determined using an automated chemiluminescent competitive immunoassay performed at Southern Cross Pathology, Monash Medical Centre, Austrailia (analytical range $0.6-127 \mathrm{nmol} / \mathrm{l}$ ). The animals were perfusion fixed with $10 \%(\mathrm{v} / \mathrm{v})$ buffered formalin after a saline washout at physiological pressure $(110-130 \mathrm{mmHg})$. The uterine tissues were removed and further immersion fixed in $10 \%$ buffered formalin for $2 \mathrm{~h}$ before processing for paraffin sections.

\section{Study two}

In the second study, we developed a mouse model to mimic the endometrial endothelial cell proliferation observed during early pregnancy (study one). Mice were bilaterally ovariectomized following anaesthesia with Avertin (as above), before being separated into four treatment groups. The dose and schedule of hormone treatment was modified from previous studies (Martin \& Finn 1968, Heryanto \& Rogers 2002, Heryanto et al. 2003).

All animals were left for 7 days following ovariectomy to allow regression of the endometrium. One group of mice were treated with a single s.c. injection of oestradiol-17 $\beta$ $(100 \mathrm{ng} / 100 \mu \mathrm{l}$ peanut oil), a no-treatment day, and three consecutive daily s.c. injections of progesterone $(1 \mathrm{mg} / 100 \mu \mathrm{l}$ peanut oil), before dissection $24 \mathrm{~h}$ after the final hormone injection (Fig. 1). Other groups were injected with either the vehicle $(100 \mu \mathrm{L}$ peanut oil), oestradiol-17 $\beta$, or progesterone injections only. All mice were dissected on day 13 following ovariectomy. Four hours prior to dissection, the mice received an intraperitoneal 


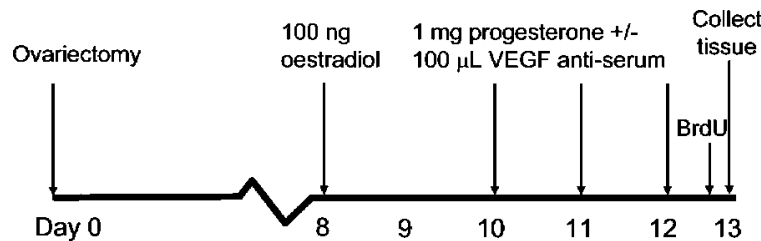

Figure 1 Experimental protocol for exogenous hormone treatment of ovariectomized mice. Study two: One group of mice $(n=5)$ were treated with a single injection of $17 \beta$-oestradiol (100 ng) on day eight after ovariectomy, followed by a day without treatment and three consecutive daily injections of progesterone $(1 \mathrm{mg})$. Other groups were treated with either the vehicle $(n=5), 17 \beta$-oestradiol $(n=5)$ or progesterone injections only $(n=5)$. All animals were dissected on day 13 , four hours after a bromodeoxyuridine (BrdU) injection. Study three: Groups of mice were treated with $17 \beta$-oestradiol (100 ng) and progesterone (1 mg) or progesterone only (as in study two) with or without concurrent treatment with a vascular endothelial growth factor (VEGF) anti-serum $(200 \mu \mathrm{l})(n=6$ in all groups).

injection of BrdU. Blood collection and perfusion fixation were as described for study one.

\section{Study three}

To investigate if progesterone-induced angiogenesis was mediated by VEGF, study two was modified and repeated. As in study two, mice were treated with the single oestradiol injection and three consecutive daily progesterone injections, or the progesterone injections only. Further groups were treated in the same way with the addition of three consecutive daily i.p. injections of rabbit polyclonal VEGF anti-serum (raised in rabbit against mouse VEGF $_{164}$, $200 \mu \mathrm{l}$ ) given concurrently with the progesterone (Rabbani \& Rogers 2001).

To confirm the efficacy of the VEGF anti-serum, a previously published protocol illustrating that oestrogeninduced endothelial cell proliferation was inhibited by VEGF anti-serum, was also performed (Heryanto et al. 2003). Ovariectomised mice received a single s.c. injection of oestradiol-17 $\beta(100 \mathrm{ng} / 100 \mu \mathrm{l}$ peanut oil) with or without an i.p. injection of VEGF anti-serum $(200 \mu \mathrm{l})$. Mice were dissected $24 \mathrm{~h}$ later, $4 \mathrm{~h}$ after a BrdU injection. Blood collection and perfusion fixation were as described for study one.

\section{Immunohistochemistry}

CD31/BrdU double immunostaining for visualisation of blood vessels and proliferating cells

Following dewaxing and rehydration, sections $(3 \mu \mathrm{m})$ were incubated with $0.1 \%(1 \mathrm{mg} / \mathrm{ml})$ pepsin in $3 \%$ acetic acid for $10 \mathrm{~min}$ at $37^{\circ} \mathrm{C}$, followed by protein blocking solution (PBA, Immunon Shandon, PA, USA) to prevent non-specific binding. The sections were then incubated with rat monoclonal anti-mouse CD31 $(5 \mu \mathrm{g} / \mathrm{ml}$ in $1 \%$ bovine serum albumin in phosphate buffered saline (BSA/PBS); BD PharMingen, San Diego, CA, USA) for $1 \mathrm{~h}$ at $37^{\circ} \mathrm{C}$. The sections were incubated for a further hour at room temperature in biotinylated goat anti-rat $\lg \mathrm{G}$ (1:200 in 1\% BSA/PBS, Chemicon, Temecula, CA, USA). CD31 immunostaining was visualized by incubating the sections in alkaline phosphatase conjugated strepavidin (DakoCytomation, Carpenteria, CA, USA) for $15 \mathrm{~min}$, followed by $10 \mathrm{~min}$ in vector blue alkaline phosphatase chromagen (Vector Laboratories, Burlingame, CA, USA). The sections were then incubated in $1.5 \mathrm{M} \mathrm{HCL}$ for $15 \mathrm{~min}$ at $37^{\circ} \mathrm{C}$, followed by a further incubation in $0.1 \mathrm{M}$ borax buffer $(\mathrm{pH}$ 8.5) for $10 \mathrm{~min}$ at room temperature. Endogenous peroxidase was quenched with 3\% $\mathrm{H}_{2} \mathrm{O}_{2}$ in PBS for 10 min. PBA was applied for a further $10 \mathrm{~min}$. The sections were incubated for $1 \mathrm{~h}$ at room temperature in monoclonal sheep anti-BrdU $(8 \mathrm{~g} / \mathrm{ml}$ in $1 \% \mathrm{BSA} / \mathrm{PBS}$, Biodesign International, Saco Maine, USA). This was followed by a further incubation for one hour at room temperature in donkey anti-sheep $\operatorname{lgG}$ $(4 \mathrm{~g} / \mathrm{mL}$ in $1 \%$ BSA/PBS, Jackson Immuno Research Laboratories, Distributed by ALS, Melb). BrdU immunostaining was visualized by incubating the sections in strepavidin horseradish peroxidase (Dako Corp) for $15 \mathrm{~min}$, followed by $5 \mathrm{~min}$ in DAB chromagen (3,3'-diaminobenzidine, Sigma). A negative isotype matched control was prepared by replacing the CD31 primary antibody with rat $\operatorname{lgG}_{2 a}$ (BD PharMingen) and the BrdU primary antibody with sheep $\operatorname{lgG}$ (Sigma) at the same concentrations as that of the primary antibodies. A positive control section of mouse intestine was included in each batch of staining.

This protocol was refined from a number of trials using various concentrations of the CD31 and BrdU primary antibodies, differing the antigen retrieval steps and the chromagens used. We confirmed that the staining was equivalent to that obtained with the individual stains alone. The number of BrdU positive cells in epithelial and stromal endometrial compartments did not differ between serial sections stained with BrdU alone or BrdU/CD31.

Counts of proliferating cells and vessels were made using three sections at least $10 \mu \mathrm{m}$ apart. Proliferating endothelial and stromal cells were counted and expressed as a count of positively stained cells per $\mathrm{mm}^{2}$ of endometrial tissue. Proliferating luminal and glandular epithelial cells were counted and expressed as a percentage of the total number of luminal and glandular epithelial cells. Vessel profiles containing positively stained endothelial cells (identified using a $\times 40$ objective lens) were counted and expressed as a percentage of the total number of vessel profiles per section.

Blood vessel density was calculated using a $\times 20$ objective lens and expressed as the total number of positively stained vessel profiles per $\mathrm{mm}^{2}$ of endometrial tissue (density based on counts in a single section). Stromal cell density was determined by counting the total number of stromal cells per $\mathrm{mm}^{2}$ (a minimum of 250 cells were counted using a $\times 20$ objective lens). The ratio of vascular density to stromal cell density was then calculated. 


\section{VEGF immunostaining}

VEGF immunostaining was performed on deparaffinized sections. Endogenous peroxidase was quenched with 3\% $\mathrm{H}_{2} \mathrm{O}_{2}$ in methanol for $10 \mathrm{~min}$. Non-specific binding was blocked by incubating sections with PBA for $10 \mathrm{~min}$. The sections were then incubated in the primary antibody, (rabbit polyclonal anti-VEGF, $1 \mu \mathrm{g} / \mathrm{ml}$ in $1 \% \mathrm{BSA} / \mathrm{PBS}$, Santa Cruz Biotechnology, CA, USA) overnight at $4{ }^{\circ} \mathrm{C}$. Following further incubation in biotinylated goat anti-rabbit IgG (Zymed, South San Francisco, CA, USA) for 30 min at room temperature, the sections were incubated with strepavidin horseradish peroxidase for $10 \mathrm{~min}$ followed by aminoethyl carbazole chromogen (Zymed) for 5 min. A negative control was prepared by replacing the primary antibody with rabbit IgG (Sigma) at the same concentration as that of the primary antibody.

The intensity of VEGF immunostaining in the endometrial luminal and glandular epithelium and stroma was semi-quantified using a graded scale: $0=$ no staining; $1=$ very weakly positive; $2=$ weakly positive; $3=$ moderately positive; $4=$ strongly positive. Three sections of endometrium were examined per mouse.

\section{Statistics}

Statistical analysis was performed using SPSS for Windows, version 11.0 (SPSS Inc., Chicago, IL, USA). The data is expressed as a median and range and was analysed using the non-parametric Kruskal-Wallis and MannWhitney $U$ tests. A $P$ value of $<0.05$ was considered significant.

\section{Results}

\section{Study one: pregnant mice}

\section{Plasma progesterone concentrations}

As expected from previously published data, plasma progesterone concentrations increased significantly across the first 4 days of pregnancy (day 1 median $=13.8 \mathrm{nmol} / \mathrm{l}$ [range:6.7-16.7]; day $2=24.7 \mathrm{nmol} / \mathrm{l} \quad$ [21.4-27.4]; day $3=44.5 \mathrm{nmol} / \mathrm{l}[31.4-56.5] ;$ day $4=41.5 \mathrm{nmol} / \mathrm{l}$ [37.1-94.3]; KW $=14.4, P=0.002$, Fig. 2A).

\section{Cellular proliferation}

The development of a double immunohistochemistry protocol staining both proliferating cells and blood vessels allowed proliferating endothelial cells (PEC) to be differentiated from proliferating stromal cells with greater certainty than when using the single stain only (Fig. 3). In pregnant mice (prior to implantation), endometrial endothelial cell proliferation was only observed on days 3 and 4 of pregnancy (day 3 median $=142.3 \mathrm{PEC} / \mathrm{mm}^{2}$ [range: 2.3-219.4]; day $4=129.0 \mathrm{PEC} / \mathrm{mm}^{2} \quad$ [34.0-272.6]; Figs $2 \mathrm{~B}$ and 3 ). There was no significant difference in endothelial cell proliferation between days 3 and 4 of pregnancy $(P=0.9)$. Endometrial blood vessels containing proliferating endothelial cells were only observed on days 3 and 4 of pregnancy (day $3=14.9 \%$ [0.4-24.1]; day $4=17.3 \%$ [4.5-22.6]; Fig. 2C). There was no significant difference between the percentage of proliferating endothelial cells on days 3 and $4(P=0.8)$.

Moderate levels of stromal cell proliferation were observed on all four days of pregnancy, and there was no significant difference between the days $(K W=1.7$, $P=0.6$, Fig. 2D). Luminal epithelial proliferation was only observed on days 2 and 3 of pregnancy with no significant difference between these days (day $2=10.0 \%$ [5.0-19.0]; day $3=12.0 \%$ [0.0-17.0]; Fig. 2F). Glandular epithelial cell proliferation was observed on days 1 to 3 only, but again there was no significant difference among these days (day $1=1.9 \%[0.0-3.8]$; day $2=2.8 \%$ $[2.0-11.8]$; day $3=6.3 \%$ [0.9-27.1]; Fig. 2F).

\section{Density}

Vascular density in the mouse endometrium increased significantly across the first four days of pregnancy (day 1 median $=406.4$ vessel profiles $/ \mathrm{mm}^{2}$ [range: 367.3698.6]; day $4=681.7$ vessel profiles $/ \mathrm{mm}^{2}$ [568.31030.0]; $\mathrm{KW}=7.8, P=0.05$, Fig. $4 \mathrm{~A}$ ). While stromal cell density did not differ significantly across the days of pregnancy (day $1=16200$ stromal cells $/ \mathrm{mm}^{2}$ [12296-19700]; day $4=17417$ stromal cells $/ \mathrm{mm}^{2} \quad$ [7905-27059]; $\mathrm{KW}=3.7, P=0.3$, Fig. $4 \mathrm{~B}$ ), the ratio of vascular density to stromal cell density did increase significantly across the days of pregnancy (day $2=0.03 \quad[0.02-0.04]$; day $4=0.04$ [0.03-0.07]; KW =10.3, $P=0.02$, Fig. 4C).

\section{VEGF immunostaining}

VEGF immunostaining was generally low in the endometrium of pregnant mice, with the most intense VEGF tissue immunostaining seen in the glandular epithelium (day 1 median $=2$ [range: $1-2] ;$ day $2=2[0-3]$; day $3=1$ $[0-2]$; day $4=1[0-1]$, Fig. 5) with slightly less intense staining observed in the luminal epithelium (day $1=1$ $[1-1]$; day $2=1[0-1]$; day $3=1[0-1]$; day $4=0.5[0-$ 1]). The lowest level of intensity was observed in the stroma (day $1=0[0-1]$; day $2=1[0-2]$; day $3=0[0-$ $1]$; day $4=0$ [0]). VEGF tissue immunostaining did not differ significantly in intensity across the days of pregnancy in either the luminal ( $\mathrm{KW}=5.1, P=0.2)$ or glandular (KW $=4.8, P=0.2$ ) epithelium, or in the stroma $(\mathrm{KW}=2.9, P=0.4)$.

\section{Study two: ovariectomized mice treated with exogenous oestrogen and progesterone}

\section{Plasma progesterone concentration}

The plasma progesterone concentrations in mice receiving either progesterone only (median $=39.1 \mathrm{nmol} /$ l [range: 29.9-87.6]) or progesterone following oestrogen $(36.1 \mathrm{nmol} / \mathrm{l}$ [19.9-64.3]) were significantly higher than 
A
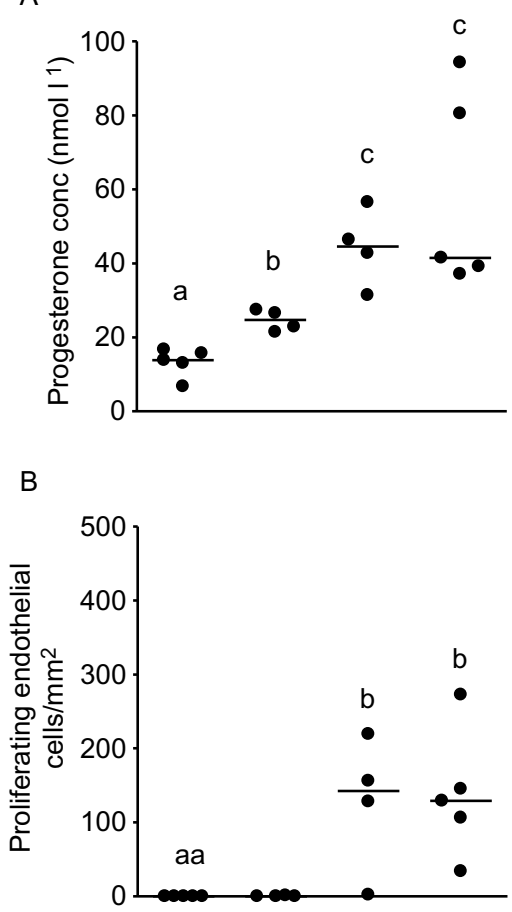

C

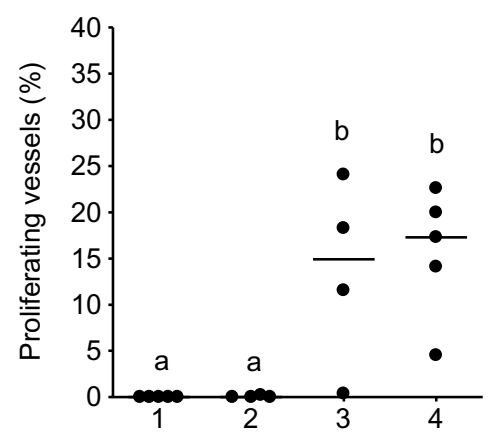

Day of pregnancy
D

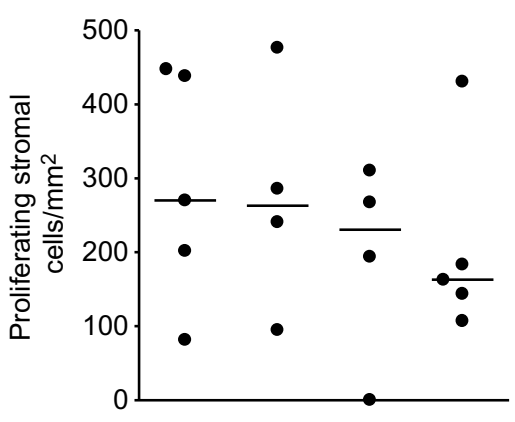

E

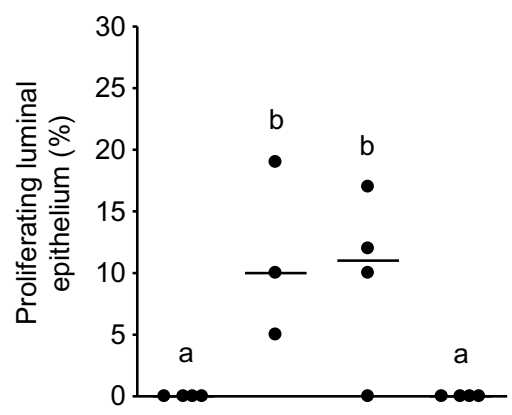

F

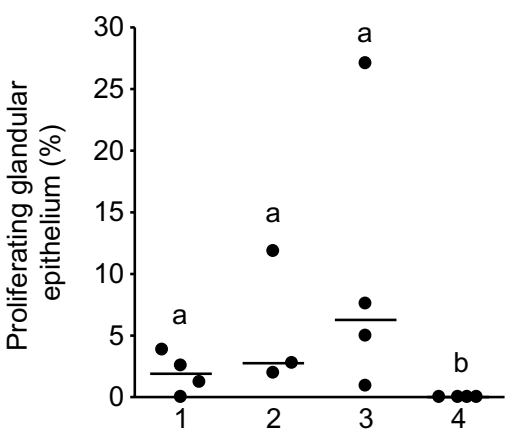

Day of pregnancy

Figure 2 Day 1 to day 4 of pregnancy in CBA/C57 mice. (A) Plasma progesterone concentrations and endometrial (B) endothelial cell proliferation, (C) percentage of proliferating vessels, (D) stromal cell proliferation, (E) luminal epithelial cell proliferation and (F) glandular epithelial cell proliferation. Horizontal bars indicate median values $(n=3-5)$. Each dot represents an individual mouse. Days that do not share a letter in common are significantly different $(P<0.05)$.

those in mice treated with vehicle $(3.8 \mathrm{nmol} / \mathrm{l}[2.9-6.3])$ or oestrogen alone $(5.6 \mathrm{nmol} / \mathrm{I}$ [4.4-6.5]; $\mathrm{KW}=13.8$, $P=0.003$, Fig. 6A). In the progesterone treated mice, plasma progesterone concentrations were similar to those in mice on days 3 and 4 of pregnancy.

\section{Cellular proliferation}

There was a significant difference in the amount of endometrial endothelial cell proliferation among mice treated with different hormone regimes $(\mathrm{KW}=14.0, P=0.003$, Fig. 6B). The highest number of proliferating endothelial cells was observed in mice treated with progesterone only $\quad\left(\right.$ median $=97.3 \mathrm{PEC} / \mathrm{mm}^{2} \quad$ [range: 60.8-203.4]).
Pretreatment of the endometrium with oestrogen significantly inhibited the proliferation seen with progesterone alone (41.0 $\mathrm{PEC} / \mathrm{mm}^{2}$ [8.9-86.9]; $\left.P=0.05\right)$. The percentage of endometrial blood vessels containing proliferating cells also differed significantly among mice treated with different hormone regimes $(\mathrm{KW}=14.0, P=0.003$, Fig. $6 \mathrm{C})$. The highest number of vessels containing proliferating cells was observed in mice treated with progesterone alone. However, unlike the data on proliferating endothelial cells per $\mathrm{mm}^{2}$, there was no significant difference in the percentage of vessel profiles containing proliferating cells between mice treated with progesterone alone and mice treated with progesterone following oestrogen 


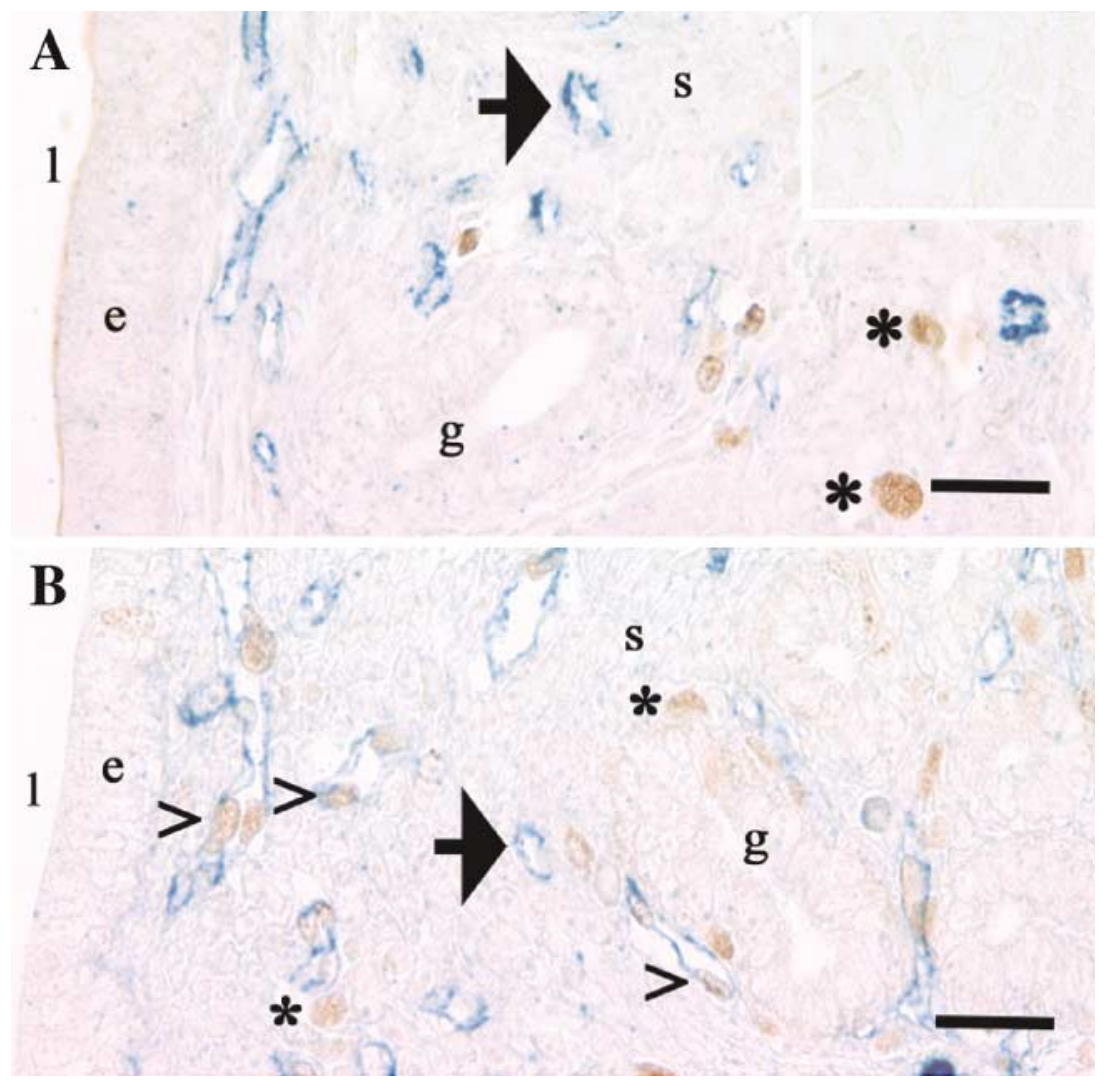

Figure 3 Representative photomicrographs of endometrium from pregnant CBA/C57 mice immunostained with both CD31 and BrdU antibodies from (A) day 1 and (B) day 3 of pregnancy. Asterisks indicate proliferating stromal cells, hollow arrow heads indicate proliferating endothelial cells, large arrows indicate blood vessel profiles. Inset, negative control section (rat IgG for CD31 and sheep IgG for BrdU); e, luminal epithelium; g, gland; I, uterine lumen; s, stroma. Bar represents $20 \mu \mathrm{m}$. priming (progesterone only: 9.0\% [5.8-17.5]; oestrogen plus progesterone: $5.4 \%[1.0-10.4] ; P=0.09)$.

Endometrial stromal cell proliferation did not differ significantly among mice treated with different hormone regimes $(\mathrm{KW}=0.70, P=0.9$, Fig. 6D). However, there was much less stromal cell proliferation in all of the treatment groups than that observed in the pregnant mice. Pretreatment of the endometrium with oestrogen prior to progesterone administration, did not have a significant effect on proliferating stromal cells (PSC), compared with mice treated with progesterone alone (progesterone alone: 50.1 PSC $/ \mathrm{mm}^{2}$ [39.2-102.6]; oestrogen plus progesterone: 46.12 PSC $/ \mathrm{mm}^{2}$ [12.6-120.8]; $P=1.0$ ). Proliferating luminal epithelial cells were only seen in mice treated with either the vehicle or with oestrogen alone, and there was no significant difference between these two groups (vehicle: $1.3 \%$ [0.0-6.5]; oestrogen only: 1.3\% [0.0-5.2]; Fig. 6E). Proliferating glandular epithelial cells were also only seen in mice treated with either the vehicle or oestrogen alone, (vehicle: 4.1\% [0.0-9.7]; oestrogen only: $6.9 \%$ [3.0-9.3]) and like the luminal epithelium, there was no significant difference between theses two groups (Fig. 6F).

\section{Density}

Vascular density differed significantly among the treatment groups $(\mathrm{KW}=8.6, P=0.04$, Fig. 7A). There was decreased density in the mice treated with oestrogen $\left(\right.$ median $=750$ vessels $/ \mathrm{mm}^{2} \quad$ [range: 407-845] $)$ in comparison to those treated with progesterone only (1035 vessels $/ \mathrm{mm}^{2}$ [865-1304]; $\left.P=0.02\right)$ or progesterone after oestrogen priming (728 vessels $/ \mathrm{mm}^{2} \quad[672-863]$; $P=0.01)$.

Stromal cell density differed significantly among the treatment groups ( $\mathrm{KW}=9.9, P=0.02$, Fig.7B). The highest stromal cell density was observed in the mice treated with oestrogen alone. The mice treated with both progesterone alone and progesterone following oestrogen priming, had significantly decreased stromal cell density compared with the mice treated with oestrogen only (oestrogen alone: 36016 stromal cells/mm² [29750-38571 stromal]; progesterone alone: 24238 stromal cells $/ \mathrm{mm}^{2}$ [15467-27346]; $P=0.01$; oestrogen plus progesterone: 23458 stromal cells $/ \mathrm{mm}^{2}$ [19179-27308]; $\left.P=0.01\right)$. The stromal cell density in the mice that were treated with progesterone with and without oestrogen priming was of the same order as that seen in the pregnant mice. The ratio of vascular density to stromal cell density was significantly lower in the mice treated with oestrogen only (0.020 [0.014-0.022]) compared with those that received progesterone alone $(0.042$ [0.035-0.054]; $P=0.02)$ or progesterone following oestrogen priming (0.034 [0.0250.045]; $P=0.01$; Fig. 7C).

\section{VEGF immunostaining}

Similar to the pregnant mouse, the most intense VEGF tissue immunostaining was observed in the glandular 
A

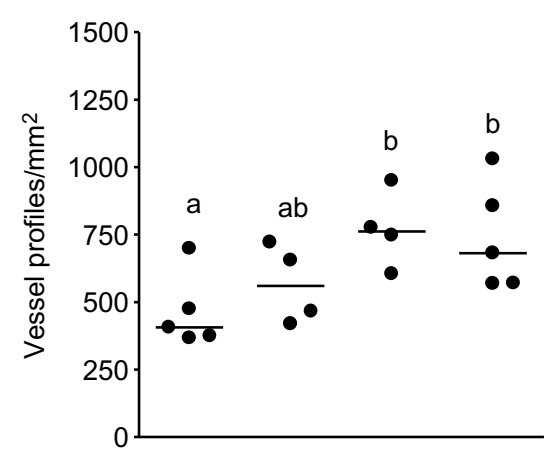

B

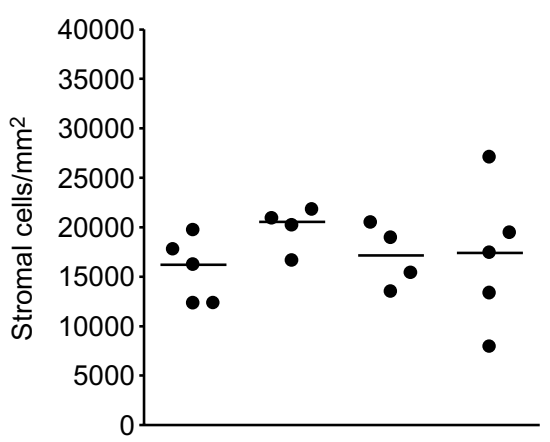

C

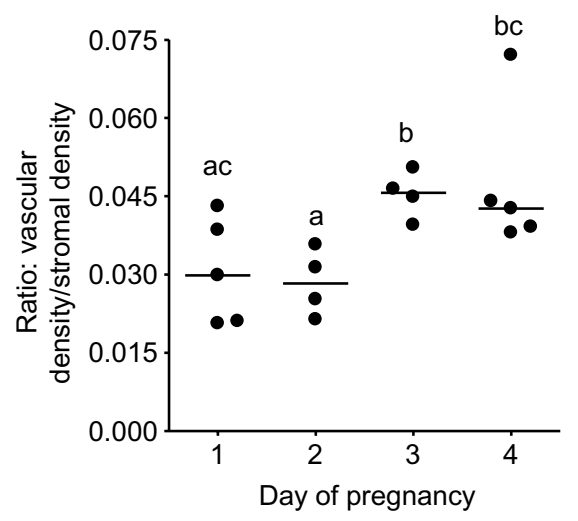

Figure 4 Day 1 to day 4 of pregnancy in CBA/C57 mice: (A) Endometrial vascular density, (B) stromal cell density and (C) the ratio of vascular density to stromal cell density. Horizontal bars indicate median values $(n=4-5)$. Each dot represents an individual mouse. Days that do not share a letter in common are significantly different $(P<0.05)$.

epithelium with slightly less intense staining observed in the luminal epithelium. The lowest level of intensity was found in the stroma of the endometrium. The intensity of VEGF tissue immunostaining did not differ significantly among the treatment groups in either the glandular epithelium ( $\mathrm{KW}=3.4, P=0.3$ ) or the stroma ( $\mathrm{KW}=7.5$, $P=0.06$ ). In the luminal epithelium, there was a significant increase in the intensity of VEGF immunostaining in the mice treated with progesterone or progesterone following oestrogen compared with the mice treated with either the vehicle or with oestrogen alone (vehicle: median $=1$ [range: $1-2]$; oestrogen only: 1 [1-2]; progesterone only: 2 [2-3]; oestrogen plus progesterone: 2.5 [2-3]; KW $=12.8, P=0.005$, Fig. 7D).

\section{Study three: ovariectomized mice treated with exogenous oestrogen and progesterone with and without VEGF anti-serum}

\section{Cellular proliferation}

As was seen in study two, there was a significant difference in the amount of endometrial endothelial cell proliferation among the treatment groups $(\mathrm{KW}=8.8$, $P=0.03$, Fig. $8 \mathrm{~A})$. The highest number of proliferating endothelial cells was observed in the mice treated with progesterone only (308.5 PEC/mm ${ }^{2}$ [126.5-344.8]) and again, pretreatment of the endometrium with oestrogen inhibited the proliferation seen with progesterone alone (32.1 PEC/mm ${ }^{2}$ [23.9-48.1]; $P=0.01$ ). Although there was no significant difference between the mice that were treated with progesterone alone and those mice treated with progesterone plus VEGF anti-serum $\left(47.7 \mathrm{PEC} / \mathrm{mm}^{2}\right.$ [38.9-463.6]; $P=0.2$ ) there was one outlier in the group of mice that received both progesterone and VEGF antiserum. This value was much higher than any other result within the treatment group and in comparison with any of the other treatment groups both in this and other studies. When this outlier was removed from the analysis, the addition of VEGF anti-serum significantly inhibited progesterone-induced proliferation $\left(46.8 \mathrm{PEC} / \mathrm{mm}^{2}\right.$ [38.9128.0]; $P=0.04)$. VEGF anti-serum did not significantly inhibit the proliferation observed in the mice that were treated with progesterone following oestrogen priming $(P=0.6)$.

In the experiment used to validate the efficacy of the VEGF anti-serum, the endometrial endothelial cell proliferation stimulated within $24 \mathrm{~h}$ of oestrogen treatment was completely inhibited when VEGF anti-serum was administered (oestrogen only: median $=179.7 \mathrm{PEC} / \mathrm{mm}^{2}$ [range: 10.5-307.8]; oestrogen and VEGF anti-serum: no proliferation; $P=0.03$ ). This indicated that the VEGF anti-serum was efficacious.

This same outlier value also prevented significance being obtained when the percentage of endometrial blood vessels containing proliferating cells was compared between the mice treated with progesterone alone and the mice treated with both progesterone and VEGF anti-serum (progesterone only: 29.6\% [20.1-36.1]; progesterone plus VEGF anti-serum: 5.6\% [5.0-34.0]; $P=0.1$, Fig. 8B). When this outlier was omitted, there was a significant difference between the mice treated with progesterone only and those treated with progesterone and VEGF antiserum $(P=0.02)$. VEGF anti-serum did not significantly affect the percentage of blood vessels containing proliferating cells in the mice treated with progesterone following oestrogen priming $(P=0.3)$. 


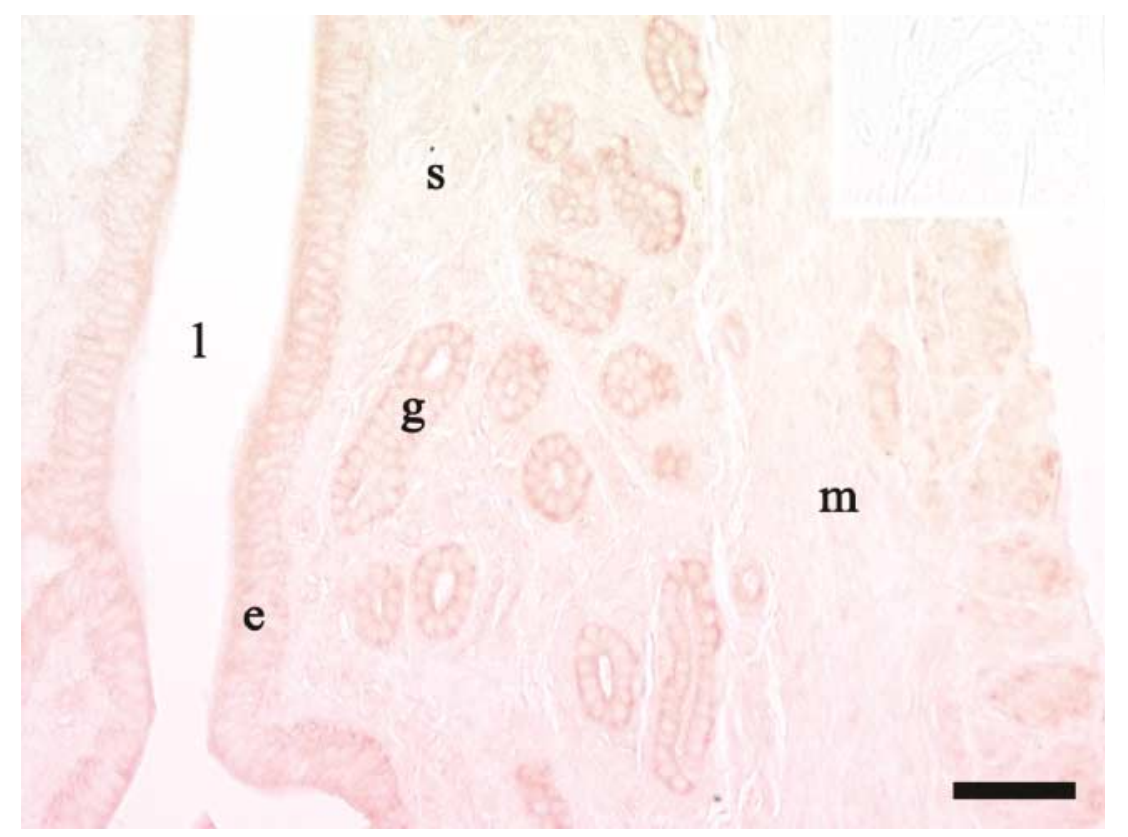

Figure 5 Representative photomicrograph of endometrium immunostained for VEGF from an ovariectomized mouse treated with progesterone and oestradiol. Inset, negative control section (rabbit IgG); e, luminal epithelium; g: glandular epithelium; I: uterine lumen; m: myometrium; s: stroma; Bar represents $50 \mu \mathrm{m}$.

Consistent with the second study, there was very little stromal cell proliferation and no significant difference was observed among the treatment groups $(\mathrm{KW}=2.5$, $P=0.5$ ). The median values ranged from $39.9 \mathrm{PSC} / \mathrm{mm}^{2}$ [18.3-58.5] to $52.5 \mathrm{PSC} / \mathrm{mm}^{2}$ [32.3-140.3]. Also consistent with the second study, no glandular or luminal epithelial cell proliferation was evident (data not shown).

\section{Density}

VEGF anti-serum did not affect vascular density within the endometrium ( $\mathrm{KW}=1.7, P=0.6$, Fig. 8D). Stromal cell density did not differ significantly between the mice treated with progesterone only and the mice treated with progesterone and VEGF anti-serum $(P=0.3$, Fig. $8 \mathrm{E})$, nor between the mice treated with progesterone following oestrogen and the mice treated with progesterone and VEGF anti-serum following oestrogen $(P=0.4)$. VEGF anti-serum did not significantly affect the ratio of vascular density to stromal cell density among the treatment groups $(\mathrm{KW}=4.6, P=0.2$, Fig. 8F).

\section{VEGF immunostaining}

As in study two, VEGF immunostaining was generally low with the most intense staining observed in the glandular epithelium and the lowest level of intensity was found in the stroma. Intensity of VEGF tissue immunostaining did not differ significantly among the treatment groups in either the glandular ( $\mathrm{KW}=3.1, P=0.3$ ) or the luminal epithelium ( $\mathrm{KW}=2.9, P=0.4$ ). However, in the stroma the mice treated with oestrogen plus progesterone (median $=0.5$ [range: $0-1]$ ) had unexpectedly lower intensity of VEGF immunostaining compared with those receiving oestrogen plus progesterone and VEGF antiserum (1 [1-2]; KW = 12.7, $P=0.005$, Fig. $8 C)$.

\section{Discussion}

This study has demonstrated that progesterone stimulates endometrial endothelial cell proliferation and that this proliferation is mediated in part by VEGF. Oestrogen priming is not required for progesterone to stimulate endometrial endothelial cell proliferation and actually inhibits progesterone-induced endometrial angiogenesis. How oestrogen mediates its anti-angiogenic effect and the pathways involved in progesterone-induced endometrial angiogenesis remain unclear.

Endometrial endothelial cell proliferation occurred on days 3 and 4 of pregnancy in the mouse (prior to implantation). A similar pattern of endothelial cell proliferation has also been observed in pregnant rats (Goodger \& Rogers 1993, Rabbani \& Rogers 2001). This endothelial cell proliferation occurs concurrently with increasing plasma progesterone concentrations, which are also observed during early pregnancy in rodents (Finn \& Martin 1969, McCormack \& Greenwald 1974). Our model using ovariectomised mice was designed to investigate the endometrial angiogenic response to progesterone. Unexpectedly, the highest amount of endothelial cell proliferation was observed in the animals that were treated with progesterone alone. Oestrogen priming of the endometrium inhibited this progesterone-induced proliferation. Progesterone mediates its actions via two progesterone receptors (PR A and PR B) which are ligand-activated 
A

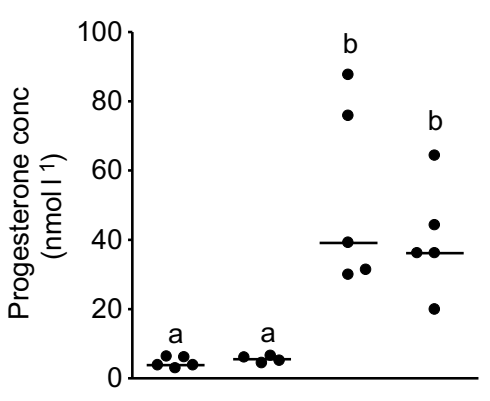

B

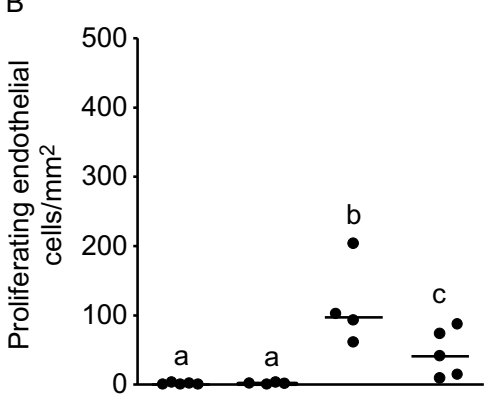

C

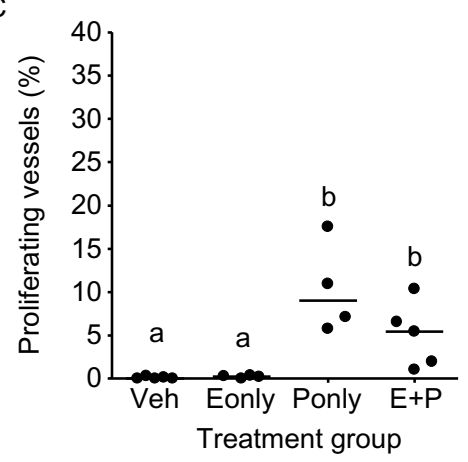

D

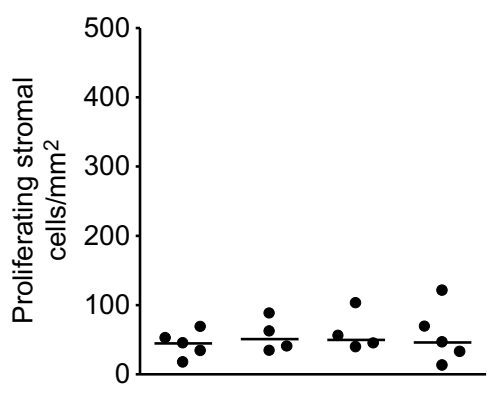

E

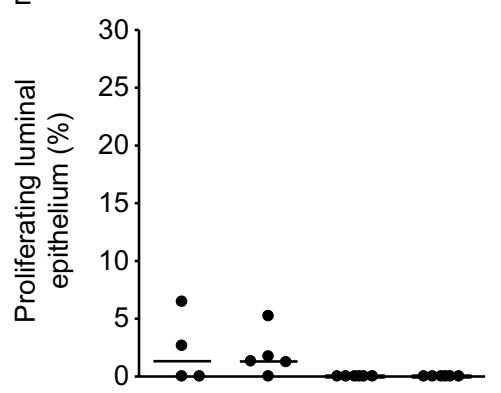

F

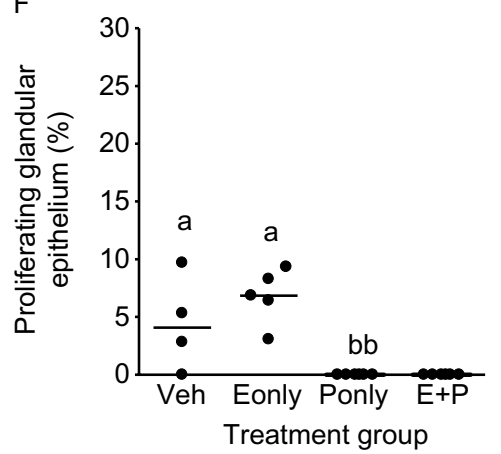

Figure 6 (A) Plasma progesterone concentrations and endometrial (B) endothelial cell proliferation, (C) percentage of proliferating vessels, (D) stromal cell proliferation, (E) luminal epithelial cell proliferation and (F) glandular epithelial cell proliferation in ovariectomised CBA/C57 mice treated with either vehicle (Veh), oestradiol (Eonly), progesterone (Ponly), or oestradiol plus progesterone $(E+P)$. Horizontal bars indicate median values $(n=4-6)$. Each dot represents an individual mouse. Groups that do not share a letter in common are significantly different $(P<0.05)$. nuclear transcription regulators (Tibbetts et al. 1998). It is widely believed that the PR gene is regulated by oestrogen through oestrogen response elements present in the promoter region of the PR (Kraus \& Katzenellenbogen 1993). Therefore, it was thought that oestrogen priming would be necessary for progesterone to have a proliferative effect on endothelial cells. The current study refutes that concept and clearly demonstrates oestrogen priming is not a prerequisite for progesterone to have an angiogenic effect on the endometrium. In the intact animal, the actions of progesterone occur naturally on a base level of endogenous oestrogen (Finn \& Martin 1969, 1970) and it has been shown in ovariectomised mice that oestrogen elicits different proliferative effects depending on the time course of its administration (Heryanto \& Rogers 2002). Heryanto \& Rogers (2002) showed that oestrogen stimulated a rapid response within $24 \mathrm{~h}$ of treatment and a second response after 48-72 h of exposure to progesterone with low dose oestrogen followed by high dose oestrogen. However, it remained unclear whether this second proliferative response was stimulated by the oestrogen, the progesterone or the combination of both. The current study clearly demonstrated that the initial proliferation induced within $24 \mathrm{~h}$ of oestrogen administration to ovariectomised mice seen by Heryanto \& Rogers, was no longer evident four days later and oestrogen was not needed for progesterone to have an angiogenic effect.

Although current in vivo studies suggest a pro-angiogenic role for progesterone, results from in vitro studies are conflicting. Vazquez et al. (1999) found that progesterone had an inhibitory effect on endothelial cell proliferation in vitro. They suggested that progestins arrest the endothelial cell cycle in $\mathrm{G}_{1}$ involving a reduction in cyclin-dependant kinase activity. However, Kayisli et al. (2004) found progesterone to have a proliferative effect on human endometrial endothelial cells (HEEC) in culture as determined by an enhanced capacity to form tubelike structures and spouts. The authors suggest this 
A

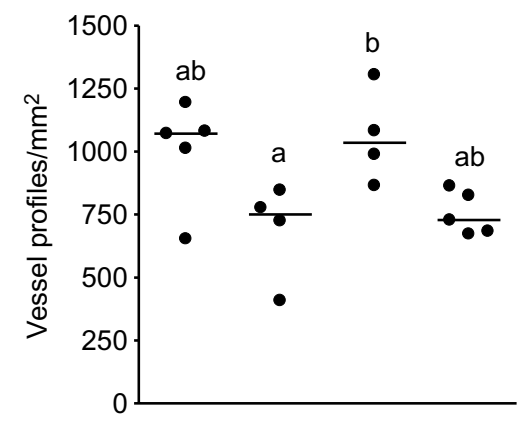

B

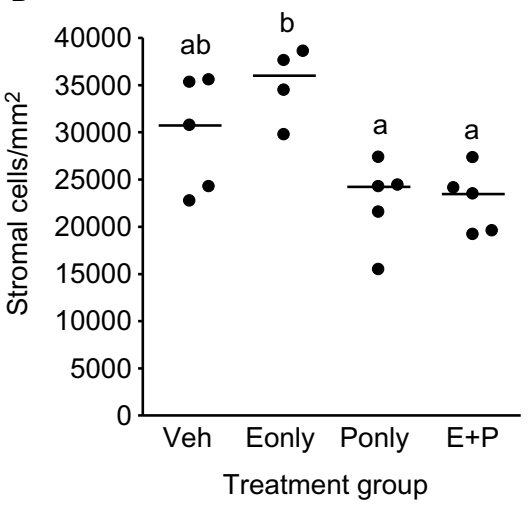

C

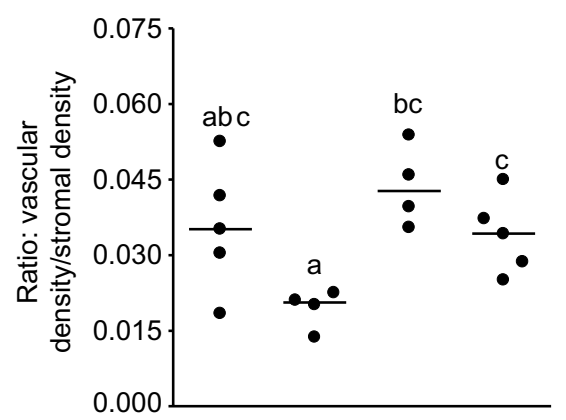

D

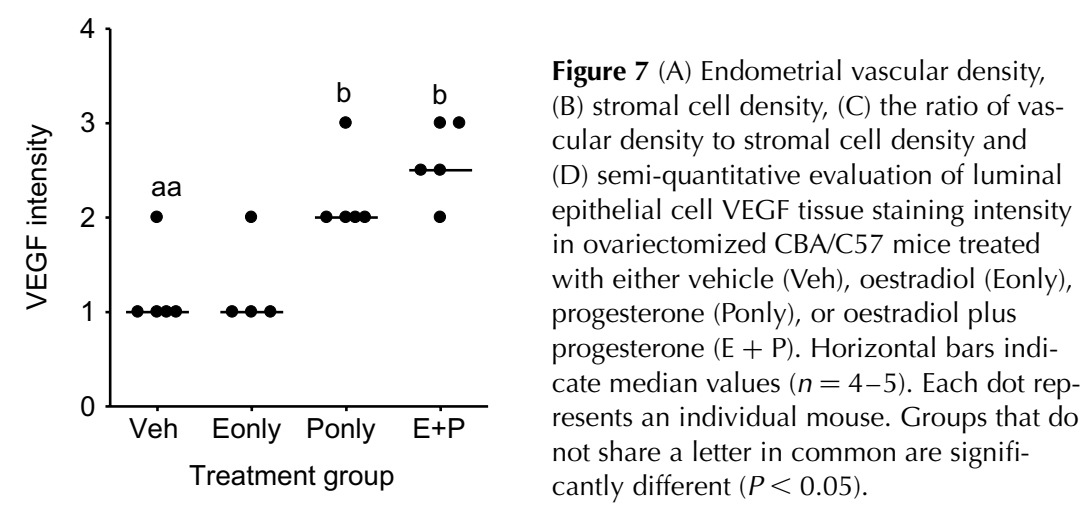

progesterone-induced proliferation is most likely caused by a direct, but non-genomic effect of progesterone in HEEC. Ma et al. (2001) found that progesterone was proliferative in vivo in ovariectomised mice and suggested the mechanism of action was via the induction of VEGF and its receptor VEGF2 (Flk1) in conjunction with neuropilin1. The current study, in agreement with Ma et al. (2001), demonstrated both the proliferative effect of progesterone and the inhibitory effect of oestrogen in endometrial angiogenesis in vivo. Progesterone-induced endometrial endothelial cell proliferation is thought to be mediated by multiple angiogenic mechanisms and regulatory factors, acting in a paracrine manner between cells within the endometrium (Greb et al. 1997, Perrot-Applant et al. 2000, Tille \& Pepper 2002). These paracrine effects are absent in vitro, which could explain the disparity between some in vitro and in vivo observations.

Current dogma considers vascular permeability to be a prerequisite for angiogenesis (Hyder \& Stancel 1999, Albrecht et al. 2003a). Progesterone, administered either alone or following oestrogen, does not appear to cause substantial tissue oedema. The stromal cell density in the mice treated with progesterone either with or without oestrogen priming, was not significantly different from that observed in the mice treated with the vehicle alone. These results concur with the findings of Ma et al. (2001) and suggest that endometrial angiogenesis is being stimulated by progesterone in the absence of substantial vascular permeability which is indicative of the different mechanisms by which short-term oestrogen or progesterone treatment stimulates blood vessel growth.

Results from this study support a role for VEGF in progesterone-induced endometrial endothelial cell proliferation. VEGF anti-serum significantly inhibited endothelial cell proliferation in the majority of mice treated with progesterone only. VEGF anti-serum did not inhibit progesterone-induced endothelial cell proliferation however, when the endometrium had been primed with oestrogen. In contrast, Heryanto et al. (2003) found that VEGF antiserum completely blocked short term oestrogen-induced endothelial cell proliferation. However, as the proliferation stimulated by progesterone was not totally blocked by the VEGF anti-serum, it would indicate that other factors in addition to VEGF are involved in mediating progesterone-induced endometrial angiogenesis. Further studies are needed to elucidate the role of other angiogenic promoters which may be acting in concert with VEGF under the influence of progesterone in the endometrium.

Although blocking VEGF had effects on endothelial cell proliferation, the effects on VEGF immunostaining were less apparent. In all three studies, the most intense VEGF tissue immunostaining was observed in the glandular and luminal epithelium. This pattern was consistent in all mice in all treatment groups with very few significant differences observed between the treatment groups and it is questionable whether these statistical differences have any biological significance. In addition, it has been shown in 
A

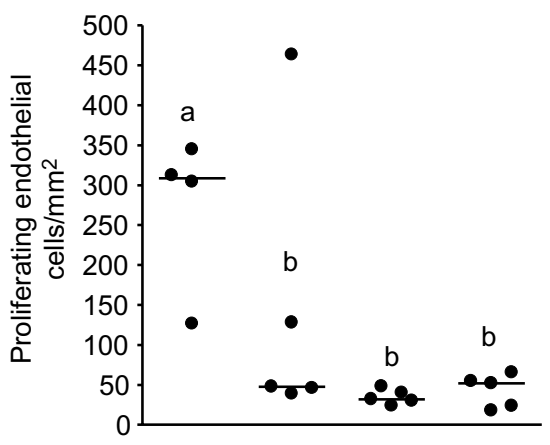

B

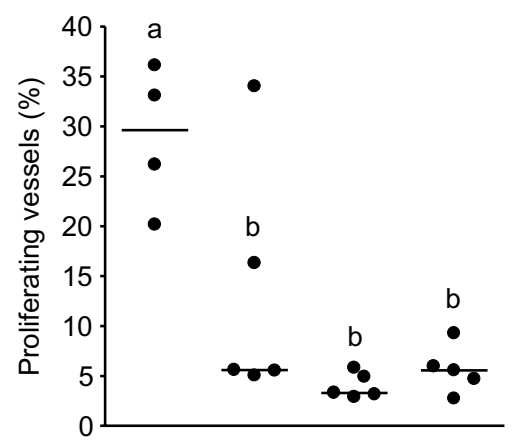

C

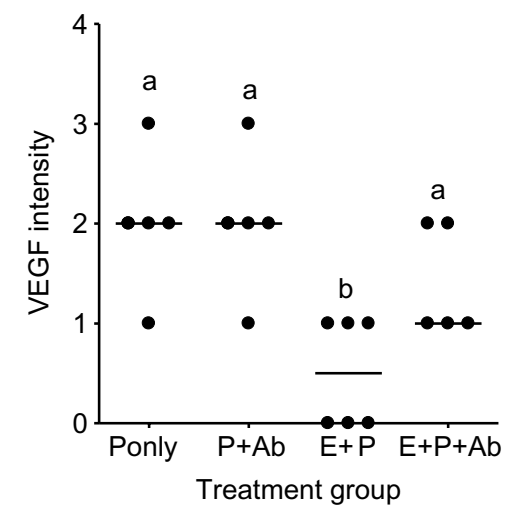

D

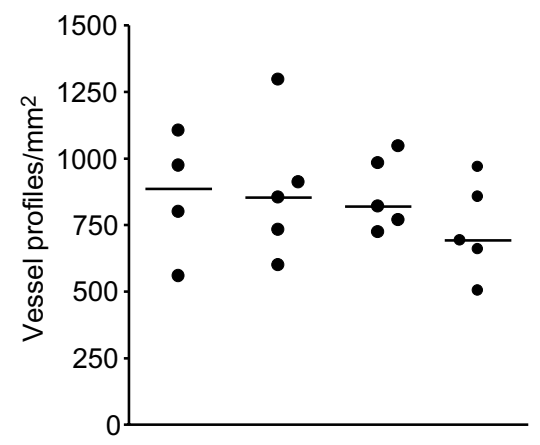

E

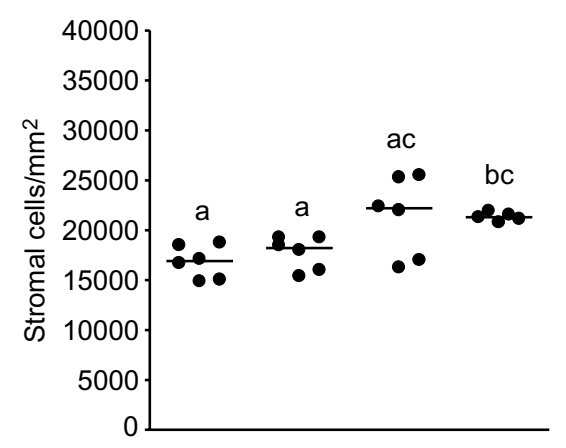

$\mathrm{F}$

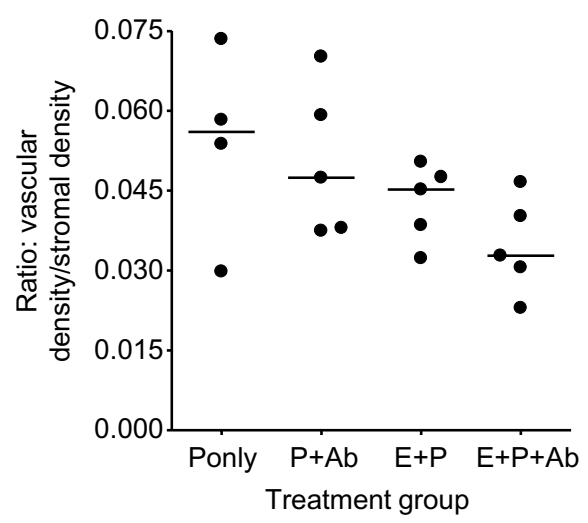

Figure 8 Quantification of (A) endometrial endothelial cell proliferation and (B) percentage of proliferating vessels, $(C)$ semiquantitative evaluation of VEGF immunostaining in endometrial stromal cells, (D) vascular density, (E) stromal cell density and $(\mathrm{F})$ the ratio of vascular density to stromal cell density in ovariectomized CBA/C57 mice treated with either progesterone (Ponly), progesterone and VEGF anti-serum $(P+A b)$, oestradiol plus progesterone $(E+P)$, or oestradiol plus progesterone and VEGF anti-serum $(E+P+A b)$. Horizontal bars indicate median values $(n=4-5)$. Each dot represents an individual mouse. Groups that do not share a letter in common are significantly different $(P<0.05)$. vitro that most epithelial VEGF is secreted apically into the uterine lumen, and is therefore unlikely to have a role in endometrial angiogenesis (Hornung et al. 1998). Further research needs to be done to examine the role of epithelial VEGF and to locate other cellular sources of VEGF (such as leukocytes) which may have a role in progesterone-induced endometrial angiogenesis. Neutrophils, eosinophils, macrophages, uterine natural killer cells and serosa-type mast cells are all located in mammalian uteri (Hunt 1994, Salamonsen et al. 2002). While these cells are best known for their role in the immune response, as well as secreting VEGF, leukocytes also express cytokines and growth factors including TNF- $\alpha$, TGF- $\alpha$ and matrix metalloproteinases which are recognized angiogenic promoters (Cassatella 1999, Salamonsen et al. 2002). One or more of these factors may be acting in concert with
VEGF to mediate progesterone-induced endometrial angiogenesis.

Results from this study concur with published data showing that progesterone strongly opposes the proliferative effects of oestrogen in the luminal epithelium (Finn \& Martin 1970, Martin et al. 1973a). Uterine luminal and glandular cell proliferation is stimulated by $17 \beta$-oestradiol which is synthesized during every estrous cycle in the mouse. Progesterone both inhibits this proliferation and induces the epithelial cells to differentiate in preparation for implantation (Tong \& Pollard 1999). In this study, both luminal and glandular epithelial proliferation was inhibited by progesterone. In the pregnant mice, no epithelial cell proliferation was observed on day 4 of pregnancy when plasma progesterone concentrations are high. In the ovariectomised mice, progesterone completely 
inhibited the epithelial cell proliferation observed in the mice treated with the peanut oil vehicle alone.

Early work by Finn \& Martin (1967) showed that there is increased stromal cell proliferation in the mouse uterus in preparation for implantation. It has been thought that both the proliferative effects of progesterone in stromal cells and the antiproliferative effects of progesterone in the luminal epithelium are due to an oestrogen-dependant up-regulation of stromal PR which in turn acts in a paracrine manner to inhibit PR expression in the luminal epithelium (Tibbetts et al. 1998, Kurita et al. 2000). PR expression in glandular epithelium however, is regulated by negative feedback by progesterone. Using wild-type and PR null mutant mice, Tibbetts et al. (1998) demonstrated the compartment-specific regulation of PR by oestrogen. While the results of the current study are in agreement with the antiproliferative effects of progesterone on endometrial epithelium, they do not support progesterone having a proliferative effect on endometrial stroma. In this study there was no significant increase in stromal cell proliferation in response to progesterone. Endometrial stromal cell proliferation did not significantly change across the days of pregnancy in study one, and was not different between the treatment groups in either study two or study three. Due to the development of the double staining immunohistochemistry protocol, proliferating endothelial cells were able to be clearly visualized within blood vessel profiles. Many proliferating cells were identified as endothelial cells which would otherwise have been mistakenly identified as stromal cells. It is possible that in the previous studies that found progesterone stimulated endometrial stromal cell proliferation (Martin \& Finn 1968, Martin et al. 1973b, Rider et al. 2003), endothelial cells may have been mistakenly identified as stromal cells.

In conclusion, the present study demonstrated that endometrial endothelial cell proliferation increased in concert with increasing plasma progesterone concentrations in early pregnancy in the mouse. The study showed that progesterone induces endometrial angiogenesis in ovariectomised mice and that oestrogen is inhibitory to this process. The study also showed that this progesterone-induced endothelial cell proliferation was partly mediated by VEGF. Progesterone was found to be proliferative in both luminal and glandular epithelium but not in the stroma. Further studies are required to determine the endometrial source of the VEGF that mediates progesterone-induced angiogenesis and to investigate the other angiogenic regulators which may also be involved.

\section{Acknowledgements}

The authors wish to thank Kjiana Schwab, Fiona Lederman, Leonie Cann and the staff of the Monash Medical Centre Animal House for technical help and assistance. The study was funded by NH \& MRC Grant No. 124331. "Peter
Roger's" salary is paid by NH \& MRC Fellowship Grant No. 143805.

\section{References}

Albrecht ED, Aberdeen GW, Niklaus AL, Babischkin JS, Suresch DL \& Pepe GJ 2003a Acute temporal regulation of vascular endothelial growth/permeability factor expression and endothelial morphology in the baboon endometrium by ovarian steroids. Journal of Clinical Endocrinology and Metabolism 88 2844-2852.

Albrecht ED, Babischkin JS, Lidor Y, Anderson LD, Udoff LC \& Pepe G) $2003 b$ Effect of estrogen on angiogenesis in co-cultures of human endometrial cells and microvascular endothelial cells. Human Reproduction 18 2039-2047.

Barkhem T, Carlsson B, Nilsson Y, Enmark E, Gustafsson J \& Nilsson S 1998 Differential response of estrogen receptor $\alpha$ and estrogen receptor $\beta$ to partial estrogen agonists/antagonists. Molecular Pharmacology 54 105-112.

Cassatella MA 1999 Neutrophil-derived proteins: selling cytokines by the pound. Advances in Immunology 73 369-509.

Finn CA \& Martin L 1967 Patterns of cell division in the mouse uterus during early pregnancy. Journal of Endocrinology 39 $593-597$.

Finn CA \& Martin L 1969 Hormone secretion during early pregnancy in the mouse. Journal of Endocrinology 45 57-65.

Finn CA \& Martin L 1970 The role of the oestrogen secreted before oestrus in the preparation of the uterus for implantation in the mouse. Journal of Endocrinology 47 431-438.

Gambino LS, Wreford NG, Bertram JF, Dockery P, Lederman F \& Rogers PA 2002 Angiogenesis occurs by vessel elongation in proliferative phase human endometrium. Human Reproduction 17 1199-1206.

Goodger AM \& Rogers PA 1993 Uterine endothelial cell proliferation before and after embryo implantation in rats. Journal of Reproduction and Fertility 99 451-457.

Greb RR, Heikinheimo O, Williams RF, Hodgen GD \& Goodman AL 1997 Vascular endothelial growth factor in primate endometrium is regulated by oestrogen-receptor and progesterone-receptor ligands in vivo. Human Reproduction 12 1280-1292.

Hastings JM, Licence DR, Burton GJ, Charnock-Jones DS \& Smith SK 2003 Soluble vascular endothelial growth factor receptor 1 inhibits edema and epithelial proliferation induced by $17 \beta$-estradiol in the mouse uterus. Endocrinology 144 326-334.

Heryanto B \& Rogers PA 2002 Regulation of endometrial endothelial cell proliferation by oestrogen and progesterone in the ovariectomized mouse. Reproduction 123 107-113.

Heryanto B, Lipson KE \& Rogers PA 2003 Effect of angiogenesis inhibitors on oestrogen-mediated endometrial endothelial cell proliferation in the ovariectomized mouse. Reproduction 125 $337-346$.

Hewitt SC \& Korach KS 2000 Progesterone action and responses in the $\alpha$ ERKO mouse. Steroids $65551-557$.

Hornung D, Lebovic DI, Shifren JL, Vigne JL \& Taylor RN 1998 Vectorial secretion of vascular endothelial growth factor by polarized human endometrial epithelial cells. Fertility and Sterility 69 909-915.

Hunt JS 1994 Immunologically relevant cells in the uterus. Biology of Reproduction $50461-466$.

Hyder SM \& Stancel GM 1999 Regulation of angiogenic growth factors in the female reproductive tract by estrogens and progestins. Molecular Endocrinology 13 806-811.

Kayisli UA, Luk J, Guzeloglu-Kayisli O, Seval Y, Demir R \& Arici A 2004 Regulation of angiogenic activity of human endometrial endothelial cells in culture by ovarian steroids. Journal of Clinical Endocrinology and Metabolism 89 5794-5802.

Kraus WL \& Katzenellenbogen BS 1993 Regulation of progesterone receptor gene expression and growth in the rat uterus: modulation 
of estrogen actions by progesterone and sex steroid hormone antagonists. Endocrinology 132 2371-2379.

Kurita T, Lee KJ, Cooke PS, Taylor JA, Lubahn DB \& Cunha GR 2000 Paracrine regulation of epithelial progesterone receptor by estradiol in the mouse female reproductive tract. Biology of Reproduction 62 821-830.

Ma W, Tan J, Matsumoto H, Robert B, Abrahamson DR, Das SK \& Dey SK 2001 Adult tissue angiogenesis: evidence for negative regulation by estrogen in the uterus. Molecular Endocrinology 15 $1983-1992$.

Martin L \& Finn CA 1968 Hormonal regulation of cell division in epithelial and connective tissues of the mouse uterus. Journal of Endocrinology 41 363-371.

Martin L, Das RM \& Finn CA 1973a The inhibition by progesterone of uterine epithelial proliferation in the mouse. Journal of Endocrinology 57 549-554.

Martin L, Finn CA \& Trinder G $1973 b$ DNA synthesis in the endometrium of progesterone-treated mice. Journal of Endocrinology $\mathbf{5 6}$ 303-307.

McCormack JT \& Greenwald GS 1974 Progesterone and oestradiol$17 \beta$ concentrations in the peripheral plasma during pregnancy in the mouse. Journal of Endocrinology 62 101-107.

Perrot-Applanat M, Ancelin M, Buteau-Lozano H, Meduri G \& Bausero P 2000 Ovarian steroids in endometrial angiogenesis. Steroids 65 599-603.

Rabbani ML \& Rogers PA 2001 Role of vascular endothelial growth factor in endometrial vascular events before implantation in rats. Reproduction 122 85-90.

Rider V, Thomson E \& Seifert C 2003 Transit of rat uterine stromal cells through G1 phase of the cell cycle requires temporal and cell-specific hormone-dependent changes on cell cycle regulators. Endocrinology 144 5450-5458.

Salamonsen LA, Zhang J \& Brasted M 2002 Leukocyte networks and human endometrial remodelling. Journal of Reproductive Immunology 57 95-108.

Smith SK 1998 Angiogenesis, vascular endothelial growth factor and the endometrium. Human Reproduction Update 4 509-519.

Tibbetts TA, Mendoza-Meneses M, O'Malley BW \& Conneely OM 1998 Mutual and intercompartmental regulation of estrogen receptor and progesterone receptor expression in the mouse uterus. Biology of Reproduction 59 1143-1152.

Tille JC \& Pepper MS 2002 Mesenchymal cells potentiate vascular endothelial growth factor-induced angiogenesis in vitro. Experimental Cell Research 280 179-191.

Tong W \& Pollard JW 1999 Progesterone inhibits estrogeninduced cyclin D1 and cdk4 nuclear translocation, cyclin Eand cyclin A-cdk2 kinase activation, and cell proliferation in uterine epithelial cells in mice. Molecular Cell Biology 19 $2251-2264$

Vazquez F, Rodriguez-Manzaneque JC, Lydon JP, Edwards DP, O'Malley BW \& Iruela-Arispe ML 1999 Progesterone regulates proliferation of endothelial cells. Journal of Biological Chemistry $2742185-2192$.

Received 16 December 2004

First decision 5 January 2005

Accepted 8 March 2005 